\title{
Inflammation and Heart Rate-corrected QT Interval: Evidence for a Potentially Reversible Cause of Sudden Death in Patients with Rheumatoid Arthritis?
}

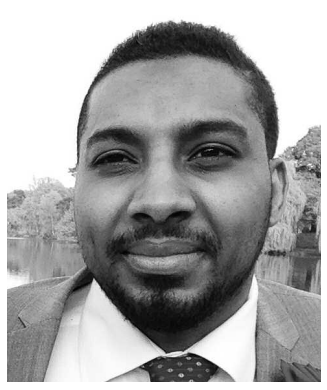

Rheumatoid arthritis (RA) is associated with an increased cardiovascular $(\mathrm{CV})$ mortality risk; however, evidence to date suggests that the presence of traditional CV risk factors, prevalent in patients with RA, only partially accounts for the increased cardiac mortality risk ${ }^{1}$. In an effort to reduce the CV morbidity and mortality associated with RA, numerous novel risk factors have been sought and implicated, including myocardial repolarization abnormalities ${ }^{2}$, autonomic dysfunction ${ }^{3}$, and inflammation ${ }^{4}$. Given that RA is associated with a doubled risk of sudden cardiac death ${ }^{1}$, an arrhythmic mechanism would seem plausible. The QT interval marks the time from onset of ventricular depolarization to the completion of repolarization and can be measured using a 12-lead electrocardiogram (ECG) from the beginning of the Q wave to the end of the T wave. Prolongation of ventricular repolarization duration increases the risk of torsade de pointes, which can lead to ventricular fibrillation and sudden death. Prolongation of heart rate-corrected QT interval (QTc) independently predicts sudden death in the general population ${ }^{5}$ and more strongly in patients with $\mathrm{RA}^{6}$. In fact, several studies have demonstrated associations between inflammation and QTc interval in $\mathrm{RA}^{2,6,7}$. Lazzerini, et al reported normalization of the QTc interval following 52 weeks of treatment with the interleukin 6 (IL-6) inhibitor tocilizumab (TCZ) in 17 patients with $\mathrm{RA}^{2}$. In this issue of The Journal, Kobayashi and colleagues ${ }^{8}$ have provided further evidence that inflammation in RA is associated with QTc prolongation, which can be reversed with the use of antiinflammatory agents.

Kobayashi, et $\mathrm{al}^{8}$ performed a cross-sectional case control study comparing QTc interval between 94 patients with RA and 42 age- and sex-matched controls. They report that QTc interval was higher in patients with RA compared to controls. In their study, patients underwent 24 weeks of treatment with TCZ, which resulted in a significant reduction in QTc interval. This well-conducted study provides direct evidence that controlling inflammation in patients with RA through
IL-6 inhibition can reduce arrhythmia risk, possibly reducing sudden death risk. Further, they demonstrated that the change in inflammation [as measured by C-reactive protein (CRP)] independently predicted the change in QTc interval. Interestingly, the association between CRP and QTc was strongest in patients who had prolonged QTc at baseline. There are a number of plausible mechanisms for the observed reduction in QTc following IL-6 inhibition. Animal studies have demonstrated that the inflammatory cytokines tumor necrosis factor- $\alpha$ (TNF- $\alpha$ ) and IL- 1 can delay cardiomyocyte action potential through effects on cardiac potassium channels $^{9}$ and calcium channels ${ }^{10}$, respectively. IL-6 inhibition reduces inflammation and results in lower concentrations of circulating TNF- $\alpha$ and IL-1. The effect of IL- 6 on cardiomyocyte potential is not known and requires further study. Another potential mechanism is the effect of inflammation on autonomic function. The QTc interval can be influenced by the autonomic nervous system; surgical sympathetic denervation ${ }^{11}$ and cholinergic stimulation ${ }^{12}$ can reduce QTc interval. Observational data show that patients with RA have reduced parasympathetic activity ${ }^{13,14}$ and heightened sympathetic activity ${ }^{3,15}$, independent of the presence of hypertension ${ }^{3,13}$. One interesting mechanism is the effect of IL-6 inhibition on cardiac remodeling. In an earlier study, Kobayashi, et al demonstrated that TCZ treatment promoted positive cardiac remodeling in patients with $\mathrm{RA}^{16}$. Cardiac magnetic resonance imaging demonstrated increases in left ventricular ejection fraction and reductions in left ventricular mass index in 20 female patients with RA after 52 weeks of IL-6 inhibition. In the

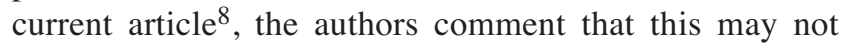
explain their present findings, given that patients demonstrated reductions in QTc interval after 24 weeks of IL-6 inhibition therapy, and only 12 weeks in an earlier study by Lazzerini, $e t a l^{2}$, supporting a process of electrical rather than structural remodeling.

This study by Kobayashi, et $a l^{8}$ provides mechanistic

See QTc treated with TCZ, page 1620

Personal non-commercial use only. The Journal of Rheumatology Copyright (c) 2018. All rights reserved. 
insight into the potential etiology of sudden death in patients with RA and provides further evidence for the link between inflammation and arrhythmia risk. Further, this work provides a number of clinical implications at the bedside for rheumatologists, cardiologists, and general physicians. First, should all patients with RA undergo routine ECG screening to assess QTc interval? What constitutes a normal QTc interval in patients with RA? While normal range values of QTc interval exist for the general population, these are lacking in the RA population and require further quantification. Can QTc interval be used as an additional criterion to support the use of biologic agents in patients with RA who fail to meet standard criteria? Given that $\beta$ blockers can reduce QTc interval in patients with long QT syndrome ${ }^{17}$ and their proven mortality benefit in patients with chronic heart failure ${ }^{18}$ and myocardial infarction ${ }^{19}$, is there a role for $\beta$ blocker use in patients with RA?

The results of this study support the hypothesis that inflammation is a potentially reversible cause of QTc prolongation, and controlling inflammation may thereby reduce the risk of sudden death. Further, in patients with prolonged QTc the presence of chronic inflammatory diseases should be sought and inflammation controlled at the earliest opportunity.

AHMED M.ADLAN (D), MBBS, PhD, MRCP(UK), Department of Cardiology,

Liverpool Heart and Chest Hospital,

Liverpool L14 3PE, UK.

Address correspondence to A.M. Adlan.

E-mail: adlan.ahmed@gmail.com

\section{REFERENCES}

1. Maradit-Kremers H, Nicola PJ, Crowson CS, Ballman KV, Gabriel SE. Cardiovascular death in rheumatoid arthritis: a population-based study. Arthritis Rheum 2005;52:722-32.

2. Lazzerini PE, Acampa M, Capecchi PL, Fineschi I, Selvi E, Moscadelli V, et al. Antiarrhythmic potential of anticytokine therapy in rheumatoid arthritis: tocilizumab reduces corrected QT interval by controlling systemic inflammation. Arthritis Care Res 2015;67:332-9.

3. Adlan AM, Paton JF, Lip GY, Kitas GD, Fisher JP. Increased sympathetic nerve activity and reduced cardiac baroreflex sensitivity in rheumatoid arthritis. J Physiol 2017;595:967-81.

4. Masoud S, Lim PB, Kitas GD, Panoulas V. Sudden cardiac death in patients with rheumatoid arthritis. World J Cardiol 2017;9:562-73.

5. Zhang Y, Post WS, Dalal D, Blasco-Colmenares E, Tomaselli GF, Guallar E. QT-interval duration and mortality rate: results from the Third National Health and Nutrition Examination Survey. Arch Intern Med 2011;171:1727-33

6. Panoulas VF, Toms TE, Douglas KM, Sandoo A, Metsios GS, Stavropoulos-Kalinoglou A, et al. Prolonged QTc interval predicts all-cause mortality in patients with rheumatoid arthritis: an association driven by high inflammatory burden. Rheumatology 2014;53:131-7.

7. Adlan AM, Panoulas VF, Smith JP, Fisher JP, Kitas GD. Association between corrected QT interval and inflammatory cytokines in rheumatoid arthritis. J Rheumatol 2015;42:421-8.

8. Kobayashi H, Kobayashi Y, Yokoe I, Kitamura N, Nishiwaki A, Takei M, et al. Heart rate-corrected QT interval duration in rheumatoid arthritis and its reduction with treatment with the interleukin 6 inhibitor tocilizumab. J Rheumatol 2018;45:1620-7.

9. Wang J, Wang H, Zhang Y, Gao H, Nattel S, Wang Z. Impairment of HERG $\mathrm{K}(+)$ channel function by tumor necrosis factor-alpha: role of reactive oxygen species as a mediator. $\mathrm{J}$ Biol Chem 2004;279:13289-92.

10. Li YH, Rozanski GJ. Effects of human recombinant interleukin-1 on electrical properties of guinea pig ventricular cells. Cardiovasc Res 1993;27:525-30

11. Li C, Hu D, Shang L, Ma S, Liu W, Li Y, et al. Surgical left cardiac sympathetic denervation for long QT syndrome: effects on QT interval and heart rate. Heart Vessels 2005;20:137-41.

12. Castro RR, Porphirio G, Serra SM, Nóbrega AC. Cholinergic stimulation with pyridostigmine reduces the QTc interval in coronary artery disease. Braz J Med Biol Res 2002;35:685-9.

13. Adlan AM, Veldhuijzen van Zanten JJCS, Lip GYH, Paton JFR, Kitas GD, Fisher JP. Cardiovascular autonomic regulation, inflammation and pain in rheumatoid arthritis. Auton Neurosci 2017;208:137-45.

14. Provan SA, Olstad DS, Solberg EE, Smedslund G, Dagfinrud H Evidence of reduced parasympathetic autonomic regulation in inflammatory joint disease: A meta-analyses study. Semin Arthritis Rheum 2018;48:134-40.

15. Dekkers JC, Geenen R, Godaert GL, Bijlsma JW, van Doornen LJ Elevated sympathetic nervous system activity in patients with recently diagnosed rheumatoid arthritis with active disease. Clin Exp Rheumatol 2004;22:63-70.

16. Kobayashi H, Kobayashi Y, Giles JT, Yoneyama K, Nakajima Y, Takei M. Tocilizumab treatment increases left ventricular ejection fraction and decreases left ventricular mass index in patients with rheumatoid arthritis without cardiac symptoms: assessed using 3.0 tesla cardiac magnetic resonance imaging. J Rheumatol 2014;41:1916-21.

17. Vincent GM, Schwartz PJ, Denjoy I, Swan H, Bithell C, Spazzolini C, et al. High efficacy of beta-blockers in long-QT syndrome type 1 : contribution of noncompliance and QT-prolonging drugs to the occurrence of beta-blocker treatment "failures." Circulation 2009; 119:215-21.

18. Chatterjee S, Biondi-Zoccai G, Abbate A, D'Ascenzo F, Castagno $D$, Van Tassell B, et al. Benefits of $\beta$ blockers in patients with heart failure and reduced ejection fraction: network meta-analysis. BMJ 2013;346:f55.

19. Bangalore S, Makani H, Radford M, Thakur K, Toklu B, Katz SD, et al. Clinical outcomes with $\beta$-blockers for myocardial infarction: a meta-analysis of randomized trials. Am J Med 2014;127:939-53.

J Rheumatol 2018;45:1609-10; doi:10.3899/jrheum.180921 